\title{
Antibody-LGI 1 autoimmune encephalitis manifesting as rapidly progressive dementia and hyponatremia: a case report and literature review
}

\author{
Xuanting $\mathrm{Li}^{1+}$, Junliang Yuan ${ }^{1 \dagger}$, Lei $\mathrm{Liu}^{2}$ and Wenli Hu${ }^{1 *}$ (D)
}

\begin{abstract}
Background: Anti leucine-rich glioma inactivated 1 (LGl1) encephalitis is a rare autoimmune encephalitis (AE), characterized by acute or subacute cognitive impairment, faciobrachial dystonic seizures, psychiatric disturbances and hyponatremia. Antibody-LGI 1 autoimmune encephalitis (anti-LGl1 AE) has increasingly been recognized as a primary autoimmune disorder with favorable prognosis and response to treatment.

Case presentation: Herein, we reported a male patient presenting as rapidly progressive dementia and hyponatremia. He had antibodies targeting LGI1 both in the cerebrospinal fluid and serum, which demonstrated the diagnosis of typical anti-LGI1 AE. The scores of Mini-Mental State Examination and Montreal Cognitive Assessment were 19/30 and 15/30, respectively. Cranial magnetic resonance images indicated hyperintensities in bilateral hippocampus. The findings of brain arterial spin labeling and Fluorine-18-fluorodeoxyglucose positron emission tomography showed no abnormal perfusion/metabolism. After the combined treatment of intravenous immunoglobulin and glucocorticoid, the patient's clinical symptoms improved obviously.
\end{abstract}

Conclusions: This case raises the awareness that a rapid progressive dementia with predominant memory deficits could be induced by immunoreactions against LGl1. The better recognition will be great importance for the early diagnosis, essential treatment, even a better prognosis.

Keywords: Autoimmune encephalitis, Limbic encephalitis, Leucine-rich glioma inactivated 1, Cognitive impairment, Hyponatremia, Arterial spin labeling

\section{Background}

Autoimmune encephalitis (AE) is an infrequently and newly described group of neurological inflammation diseases related to specific autoantibodies. Various subgroups of $\mathrm{AE}$ are distinguished by these autoantibodies, which may lead to specific clinical presentations and different prognoses [1]. Among them, anti-leucine rich glioma inactivated 1 (LGI1) encephalitis is a treatable etiology of AE. Anti-LGI1 AE is characterized by cognitive impairment or rapid progressive dementia, psychiatric disorders, faciobrachial dystonic seizures (FBDS)

\footnotetext{
* Correspondence: wenlihu3366@126.com

${ }^{+}$Xuanting Li and Junliang Yuan are joint first authors.

${ }^{1}$ Department of Neurology, Beijing Chaoyang Hospital, Capital Medical

University, Beijing 100020, China

Full list of author information is available at the end of the article
}

and refractory hyponatremia [2, 3]. It is also considered a subtype of limbic encephalitis usually occurring without any detectable paraneoplastic cause $[4,5]$. It is sensitive to the treatment of immunotherapy including steroids, intravenous immunoglobulin (IVIG) and other immunosuppression agents [6]. Unfortunately, it has often been misdiagnosed to be viral encephalitis or mental illness, which may delay immunotherapy and resulted in the deterioration of their conditions, including status epileptics and even coma [7].

Different from invasive fluorine-18-fluorodeoxyglucose positron emission tomography $\left({ }^{18} \mathrm{~F}\right.$-FDG $\left.\mathrm{PET}\right)$, arterial spin labeling (ASL), without the use of intravenous gadolinium contrast, is highly sensitive technique to detect the changes of regional cerebral blood flow (CBF) $[8,9]$. It was reported

(c) The Author(s). 2019 Open Access This article is distributed under the terms of the Creative Commons Attribution 4.0 International License (http://creativecommons.org/licenses/by/4.0/), which permits unrestricted use, distribution, and reproduction in any medium, provided you give appropriate credit to the original author(s) and the source, provide a link to the Creative Commons license, and indicate if changes were made. The Creative Commons Public Domain Dedication waiver (http://creativecommons.org/publicdomain/zero/1.0/) applies to the data made available in this article, unless otherwise stated. 
that a novel case of anti-N-methyl-d-aspartate receptor encephalitis was characterized by cerebral regional hyperperfusion on ASL [10]. To the best of our knowledge, there was only one case using the technique of ASL to detection and follow-up of perfusion changes in anti-LGI1 AE [11].

Herein, we reported a 56-year-old man presenting as rapidly progressive dementia and hyponatremia with anti-LGI1 AE, and described the clinical manifestations, imaging findings of ASL, and treatment and outcomes. As far as we know, this is the second report using the combination of ${ }^{18} \mathrm{~F}$-FDG PET and ASL to explore the metabolism changes in anti-LGI1 AE.

\section{Case presentation}

A 56-year-old man presented with fever for three weeks and memory decline for two weeks, especially deficits in anterograde amnesia. Initial neurological examination revealed rapidly progressive cognitive impairment. The scores of Mini-Mental State Examination (MMSE) and Montreal Cognitive Assessment (MoCA) were 19/30 and $15 / 30$, respectively. No epileptic seizures occurred during the disease course.

The cerebrospinal fluid (CSF) showed mildly elevated leukocyte $(19 / \mathrm{uL}$, normal range $0-8 / \mathrm{uL}$ ) and glucose $(5.39 \mathrm{mmol} / \mathrm{L}$, normal range $2.5-4.5 \mathrm{mmol} / \mathrm{L})$, lowered chloride $(113.5 \mathrm{mmol} / \mathrm{L}$, normal range $120-130 \mathrm{mmol} / \mathrm{L})$, and a normal protein level $(44 \mathrm{mg} / \mathrm{dL}$, normal range 20 $40 \mathrm{mg} / \mathrm{dL}$ ). At the same time, the serum tests of sodium, chloride and blood glucose were $126.1 \mathrm{mmol} / \mathrm{L}, 94.2$ $\mathrm{mmol} / \mathrm{L}$ and $7.26 \mathrm{mmol} / \mathrm{L}$, respectively. The LGI1-Ab was positive $(+++)$ both in the serum and CSF (Fig. 1), however, the other biomarkers of AE (NMDAR-Ab, AMPAR2-Ab, GABA $B_{B} R-A b$, Caspr2-Ab), tumor markers (CEA, AFP, CA125, CA19-9, CA15-3, CA724, SCCAg, NSE, T-PSA, CYFRA21-1) and paraneoplastic neuronal antibodies (anti-Hu, - Ri, -Yo, -Ma/Ta, -Amphiphysin, $-\mathrm{CV} 2,-\mathrm{SOX} 1,-\mathrm{Tr}$ ) were all unremarkable. The other laboratory tests revealed within normal limits. Electroencephalogram was normal. Cranial magnetic resonance images (MRI) indicated hyperintensities in bilateral hippocampus on T2-weighted fluid-attenuated inversion recovery (Fig.1a) and diffusion weighted imaging (Fig.1b) sequences. Twelve days later, the repeat MRI showed some abnormal hyperintensities particularly in the left hippocampus (Fig.1c, d). Chest computed tomography and ${ }^{18}$ F-FDG PET showed no signs of tumor (Fig.2). One month after onset of cognitive decline, the findings of ASL and ${ }^{18}$ F-FDG PET showed no abnormal perfusion/metabolism in the bilateral hippocampus (Fig.3).

He was diagnosed with anti-LGI1 AE, with the treatment of methylprednisolone and IVIG, later with oral prednisone for six months. Fifteen days after his admission, he recovered obviously and discharged from our department with mild memory impairment. During 30

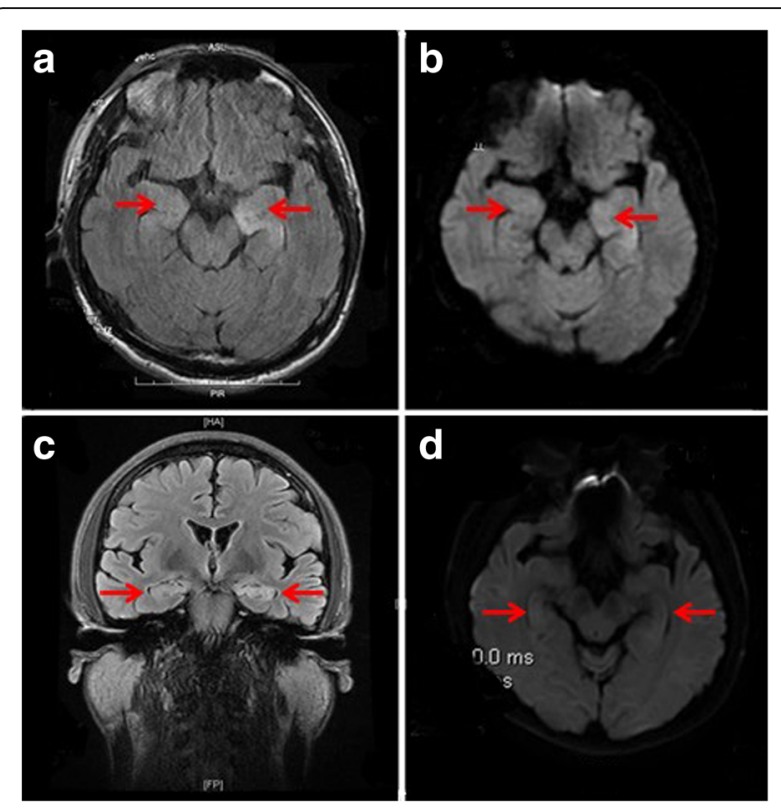

Fig. 1 Cranial magnetic resonance images (MRI) of this patient. T2weighted fluid-attenuated inversion recovery (a) and the corresponding plane in diffusion weighted imaging (b) sequences showed hyperintensities of bilateral hippocampus. Repeated MRI showed some abnormal hyperintensities particularly in the left hippocampus 12 days after the initial MRI scan (c, d)

days' follow-up, his symptoms were in complete remission with immunomodulation. The cognitive function became normal with MMSE 30/30.

\section{Discussion and conclusions}

Herein, we described a case presenting as rapidly progressive dementia and hyponatremia. The clinical manifestations, positive LGI1-Ab both in CSF and serum, neuroimaging findings, the treatable effect and favorable prognosis contributed to the diagnosis of anti-LGI1 AE. Thorough differential diagnosis of AE should be considered in patients with presentation of symptoms, such as memory impairment.

In spite of rare condition, anti-LGI1 AE is manifesting with memory deterioration, FBDS, epileptic seizures, mental disorders and hyponatremia. The hyponatremia is a characteristic feature of anti-LGI1 AE, and $60 \%$ $88 \%$ of such patients have refractory hyponatremia according to the prior studies $[3,7,12,13]$. The pathogenic mechanism is likely associated with the syndrome of inappropriate antidiuretic hormone secretion causing by the simultaneous LGI1 expression of the hypothalamus and kidney $[14,15]$. Our case was consistent with prior reports, with the lower level of sodium $126.1 \mathrm{mmol} / \mathrm{L}$, however, the hyponatremia in our case was refractory.

Besides hyponatremia, cognitive impairment is also one of common neurological disorders in anti-LGI1 AE. Memory disorder, especially short memory impairment, 


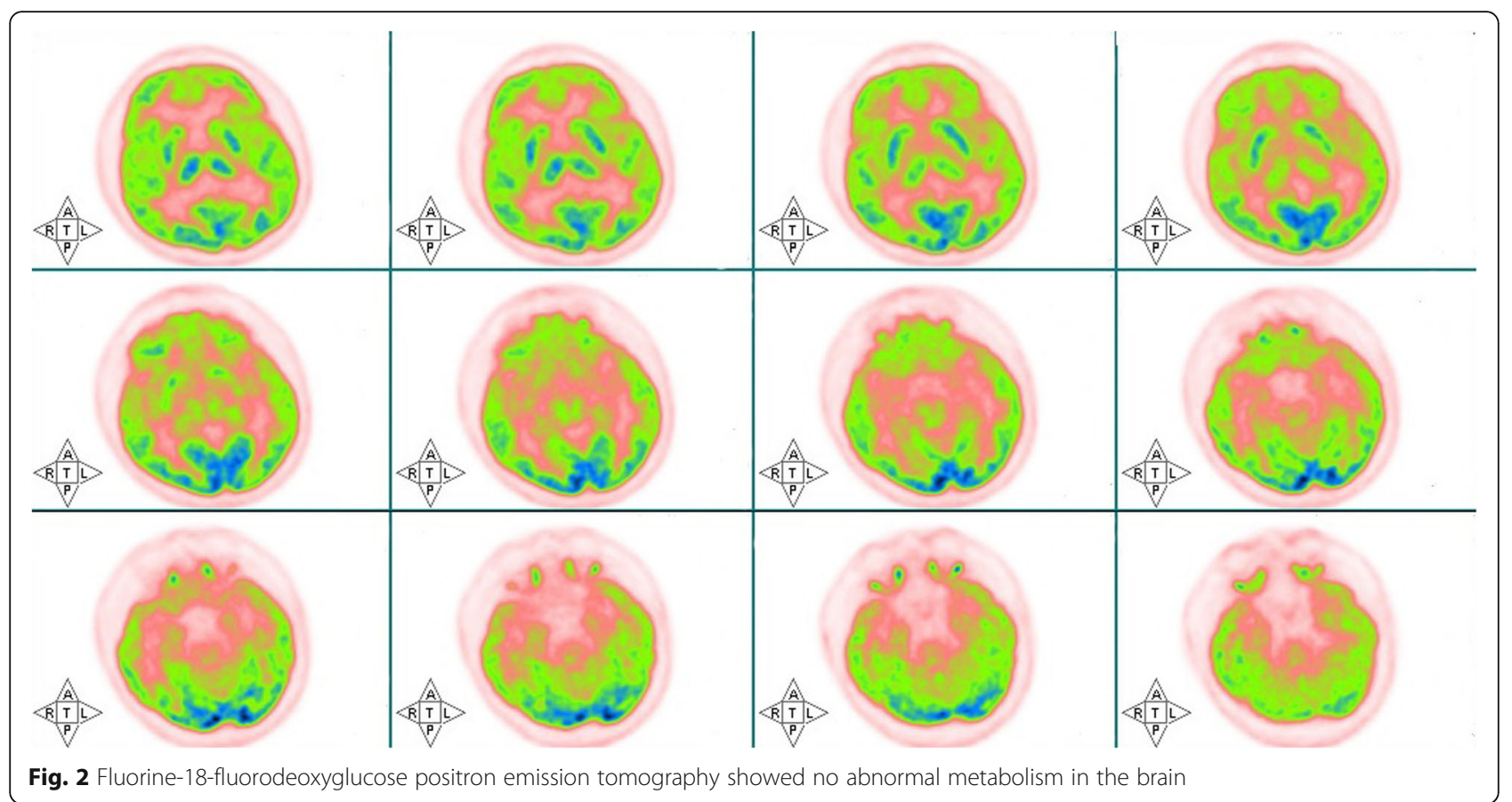

is the most prominent [16]. Up to $15 \%$ of the anti-LGI1 AE patients developed rapidly progressive cognitive dysfunction, which further increase the difficulty of the differential diagnosis with neurodegenerative disorders [17]. However, the neuroimaging features and long-term cognitive prognosis are still not well understood. The cognitive impairment of anti-LGI1 AE patients may be caused by the structural damage of hippocampal memory system [18]. Some Japanese scholars found that the influence of the interaction of LGI1-ADAM22-AMPAR on the long-term depression and long-term potentiation may play a significant part in the process of memory dysfunction [19]. Fortunately, this cognitive impairment might be prevented by early immunotherapy. The treatment with high-dose steroids, IVIG and/or plasma exchange was considered to be first-line therapy, however, the clinical remission upon methylprednisolone and IVIG does not prove therapeutic efficacy of these drugs [20].

${ }^{18}$ F-FDG PET is a useful tool to help evaluate the treatment response of encephalitis [21]. It is newly used to support the diagnosis of $\mathrm{AE}$, characterized by the hypometabolism on the parietal and occipital cortices and the hypermetabolism on the basal ganglia [21]. Another PET study also found that markedly increased

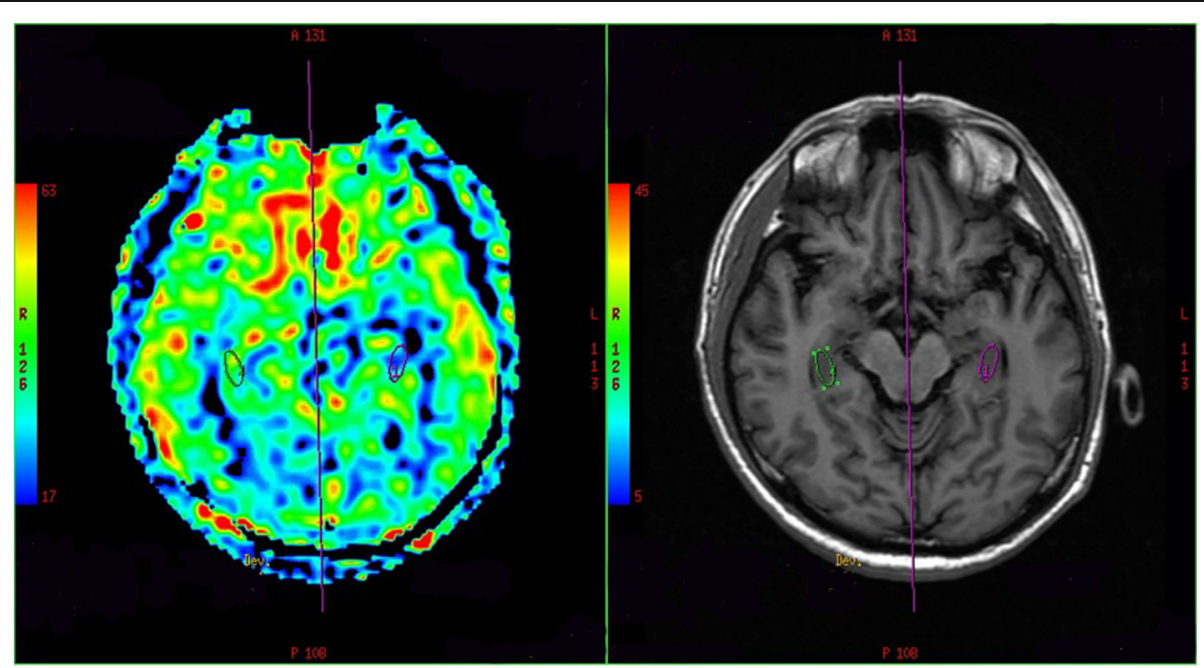

Fig. 3 Arterial spin labeling showed no abnormal perfusion in bilateral hippocampus 
FDG uptake was initially revealed in both limbic system during the acute phase of disease, and gradually decreased and eventually returned to normal after treatment [21]. Different from invasive ${ }^{18} \mathrm{~F}$-FDG PET, ASL is a noninvasive tool with high sensitivity to changes in regional $\mathrm{CBF}$ $[8,9]$. It's proposed that the areas of hyperperfusion on ASL is in accordance with the reginal enhancement in the acute and subacute inflammation processes [22]. To the best of our knowledge, there was only one case using the technique of ASL on detection and follow-up of perfusion changes in anti-LGI1 AE [11]. This case described anti-LGI1 AE with hyperperfusion in hippocampus and amygdala during the acute stage, and follow-up neuroimaging proved improvement after the treatment [11].

As for our patient, there are some strengths should be addressed. Firstly, the clinical features, the neuroimaging findings, the positive LGI1 antibodies both in CSF and serum, and the hyponatremia, were all contributed to the diagnosis of anti-LGI1 AE. Secondly, our case presented with obvious memory impairment, after the immunomodulation, the cognitive disorders fully recovered. We inferred abnormal structures in bilateral hippocampus might be associated with memory disorder. Thirdly, the refractory hyponatremia was a distinguishing feature in our case, highlighting the higher prevalence of hyponatremia in patients with anti-LGI1 AE. Fourthly, ASL is a highly sensitive tool to detect the changes of regional CBF, especially in acute stage. However, ASL and ${ }^{18}$ F-FDG PET of our case showed no abnormal perfusion/metabolism in the brain. This may be due to the fact that ASL and PET were performed four weeks after the onset and not in the acute phase. As far as we know, this is the second report using the combination of ${ }^{18}$ F-FDG PET and ASL to explore the metabolism changes in anti-LGI1 AE. Further prospective studies with larger sample sizes will be needed to utilize ASL to validate such findings.

In summary, $\mathrm{AE}$ is rare and the causes are still largely unknown. It is an under-recognized condition and favorable prognosis. Our case increases the awareness of anti-LGI1 AE, as early recognition and treatment is critical and necessary. Our case also highlights the importance of differential diagnosis and ongoing follow-up of patients with rapidly progressive dementia. Randomized clinical trials are needed in anti-LGI1 AE.

\footnotetext{
Abbreviations

${ }^{18}$ F-FDG PET: Fluorine-18-fluorodeoxyglucose positron emission tomography; AE: Autoimmune encephalitis; ASL: Arterial spin labeling; CBF: Cerebral blood flow; CSF: Cerebrospinal fluid test; FBDS: Faciobrachial dystonic seizure; IVIG: Intravenous immunoglobulin; LGI1: Leucine-rich glioma inactivated 1; MMSE: Mini-Mental State Examination; MoCA: Montreal Cognitive Assessment; MRI: Magnetic resonance image
}

\section{Funding}

This work was supported by the National Natural Science Foundation of China (81301016) and the Beijing Municipal Administration of Hospitals' Youth Programme (QML20150303). The funders had no role in the design of the study, interpretation of data or in writing the manuscript. They had contributed to the data collection.

Availability of data and materials

Not applicable.

\section{Authors' contributions}

$X T L$ and $J L Y$ examined, evaluated the patient and drafted the manuscript. $L L$ performed and interpreted the MRI studies. WLH participated in the design of the case-report and helped to draft the manuscript. All authors read and approved the final manuscript.

\section{Ethics approval and consent to participate}

The study was approved by the Institutional Ethical Committee of Beijing Chaoyang Hospital, Capital Medical University and the patient gave written informed consent prior to obtain the data.

\section{Consent for publication}

Written informed consent was obtained from the patient after treatment for publication of this case report and any accompanying images. A copy of the written consent is available for review by the Editor of this journal.

\section{Competing interests}

The authors declare that they have no competing interests.

\section{Publisher's Note}

Springer Nature remains neutral with regard to jurisdictional claims in published maps and institutional affiliations.

\section{Author details}

'Department of Neurology, Beijing Chaoyang Hospital, Capital Medical University, Beijing 100020, China. ²Department of Neurology, Beijing Tongren Hospital, Capital Medical University, Beijing 100730, China.

Received: 14 October 2018 Accepted: 1 February 2019

Published online: 07 February 2019

\section{References}

1. Honnorat J, Plazat LO. Autoimmune encephalitis and psychiatric disorders. Rev Neurol. 2018;174(4)

2. Thompson J, Bi M, Murchison AG, Makuch M, Bien CG, Chu K, et al. The importance of early immunotherapy in patients with faciobrachial dystonic seizures. Brain. 2018;141:2.

3. Irani SR, Alexander $S$, Waters $P$, Kleopa KA, Pettingill $P$, Zuliani $L$, et al. Antibodies to Kv1 potassium channel-complex proteins leucine-rich, glioma inactivated 1 protein and contactin-associated protein-2 in limbic encephalitis, Morvan's syndrome and acquired neuromyotonia. Brain. 2010;133:9

4. Vincent A, Bien CG, Irani SR, Waters P. Autoantibodies associated with diseases of the CNS: new developments and future challenges. The Lancet Neurology. 2011;10(8)

5. Kaluschke T, Johannis W, Mpotsaris A, Fink GR, Malter MP. Neurocardiac prodrome in LGl1-antibody-negative non-paraneoplastic limbic encephalitis. J Neurol Sci. 2018;391

6. Casault C, Alikhani K, Pillay N, Koch M. Jerking \& confused: leucine-rich glioma inactivated 1 receptor encephalitis. J Neuroimmunol. 2015;289.

7. Gao L, Liu A, Zhan S, Wang L, Li L, Guan L, et al. Clinical characterization of autoimmune LGI1 antibody limbic encephalitis. Epilepsy Behav. 2016;56.

8. Sierra-Marcos A, Carreno M, Setoain X, Lopez-Rueda A, Aparicio J, Donaire A, et al. Accuracy of arterial spin labeling magnetic resonance imaging (MRI) perfusion in detecting the epileptogenic zone in patients with drugresistant neocortical epilepsy: comparison with electrophysiological data, structural MRI, SISCOM and FDG-PET. Eur J Neurol. 2016;23(1)

9. Boscolo Galazzo I, Storti SF, Del Felice A, Pizzini FB, Arcaro C, Formaggio E, et al. Patient-specific detection of cerebral blood flow alterations as assessed by arterial spin labeling in drug-resistant epileptic patients. PLoS One. 2015;10(5). 
10. Sachs JR, Zapadka ME, Popli GS, Burdette JH. Arterial spin labeling perfusion imaging demonstrates cerebral hyperperfusion in anti-NMDAR encephalitis. Radiology Case Reports. 2017;12(4).

11. Espinosa-Jovel C, Toledano R, Garcia-Morales I, Alvarez-Linera J, Gil-Nagel A. Serial arterial spin labeling MRI in autonomic status epilepticus due to antiLGI1 encephalitis. Neurology. 2016;87(4).

12. Muhr P, Goldammer U, Bien CG, Bien C, Sindern E. Severe hyponatremia as precursor of LGI1 autoimmune encephalitis. Nervenarzt. 2018;89:8.

13. Irani SR, Michell AW, Lang B, Pettingill P, Waters P, Johnson MR, et al. Faciobrachial dystonic seizures precede Lgi1 antibody limbic encephalitis. Ann Neurol. 2011;69(5).

14. Lai M, Huijbers MG, Lancaster E, Graus F, Bataller L, Balice-Gordon R, et al. Investigation of $L G \mid 1$ as the antigen in limbic encephalitis previously attributed to potassium channels: a case series. The Lancet Neurology. 2010;9(8).

15. Ellison DH, Berl T. Clinical practice. The syndrome of inappropriate antidiuresis The New England journal of medicine. 2007;356:20.

16. van Sonderen A, Schreurs MW, Wirtz PW, Sillevis Smitt PA, Titulaer MJ. From VGKC to LGI1 and Caspr2 encephalitis: the evolution of a disease entity over time. Autoimmun Rev. 2016;15(10).

17. Escudero D, Guasp M, Arino H, Gaig C, Martinez-Hernandez E, Dalmau J, et al. Antibody-associated CNS syndromes without signs of inflammation in the elderly. Neurology. 2017;89(14).

18. Finke C, Pruss H, Heine J, Reuter S, Kopp UA, Wegner F, et al. Evaluation of cognitive deficits and structural hippocampal damage in encephalitis with leucine-rich, glioma-inactivated 1 antibodies. JAMA Neurol. 2017:74(1).

19. Ohkawa T, Fukata Y, Yamasaki M, Miyazaki T, Yokoi N, Takashima H, et al. Autoantibodies to epilepsy-related LGI1 in limbic encephalitis neutralize LG11-ADAM22 interaction and reduce synaptic AMPA receptors. J Neurosci. 2013;33:46.

20. Celicanin M, Blaabjerg M, Maersk-Moller C, Beniczky S, Marner L, Thomsen C, et al. Autoimmune encephalitis associated with voltage-gated potassium channels-complex and leucine-rich glioma-inactivated 1 antibodies - a national cohort study. European journal of neurology. 2017;24:8.21. Park S, Choi H, Cheon GJ, Wook Kang K, lee DS. 18F-FDG PET/CT in anti-LGl1 encephalitis: initial and follow-up findings. Clin Nucl Med. 2015;40:2.

21. Tripathi M, Tripathi M, Roy SG, Parida GK, Ihtisham K, Dash D, et al. Metabolic topography of autoimmune non-paraneoplastic encephalitis. Neuroradiology. 2018;60(2)

22. Ho ML. Arterial spin labeling: clinical applications. Journal of neuroradiology Journal de neuroradiologie. 2018;45:5.

Ready to submit your research? Choose BMC and benefit from:

- fast, convenient online submission

- thorough peer review by experienced researchers in your field

- rapid publication on acceptance

- support for research data, including large and complex data types

- gold Open Access which fosters wider collaboration and increased citations

- maximum visibility for your research: over $100 \mathrm{M}$ website views per year

At BMC, research is always in progress.

Learn more biomedcentral.com/submissions 